\title{
TCP1 regulates PI3K/AKT/mTOR signaling pathway to promote proliferation of ovarian cancer cells
}

\author{
Huixi Weng ${ }^{\dagger}$, Xiushan Feng ${ }^{\dagger}$, Yu Lan and Zhiqun Zheng ${ }^{*}$ (10
}

\begin{abstract}
Objective: TCP1 is one of the eight subunits of the TCP1 ring complex (TRiC) or the multi-protein mammalian cytosolic chaperone complex. TRiC participates in protein folding and regulates the expression of multiple signaling proteins and cytoskeletal components in cells. Although the clinical importance of its subunits has been clarified in various carcinomas, the function of TCP1 in ovarian cancer $(\mathrm{OC})$ remains unclear. We aimed to identify the association between the expression of TCP1 and the development of epithelial OC (EOC) and patient prognosis, and explore the underlying mechanisms of TCP1 on the tumor progression of OC cells.

Methods: TCP1 protein expression was tested in various ovarian tissues by immunohistochemistry, and the correlation between TCP1 expression and clinical physiologic or pathologic parameters of patients with EOC was analyzed. The relationship between TCP1 expression and the prognosis of patients with OC was investigated and analyzed using the Kaplan-Meier (KM) plotter online database. The expression level of TCP1 was then tested in different OC cell lines by Western blotting. Further, a model using OC cell line A2780 was constructed to study the functions of TCP1 in growth, migration, and invasion of human EOC cells. Finally, the possible regulating signaling pathways were discussed.

Results: TCP1 protein expression in OC or borderline tissues was significantly higher than that in benign ovarian tumors and normal ovarian tissue. The upregulated expression of TCP1 in OC was positively associated with the differentiation grade and FIGO stage of tumors and predicted poor clinical outcomes. Compared with IOSE-80 cells, TCP1 protein was overexpressed in A2780 cells. TCP1 knockdown using shRNA lentivirus inhibited the viability of A2780 cells. Western blotting showed that the phosphatidylinositol-3 kinase (PI3K) signaling pathway was activated in the tumor invasion in EOC driven by TCP1.
\end{abstract}

Conclusion: Upregulated TCP1 is correlated with the poor prognosis of patients with OC. The mechanism of cancer progression promoted by TCP1 upregulation may be linked to the activation of the PI3K signaling pathway, and TCP1 may serve as a novel target for the treatment of OC.

Keywords: TCP1, Ovarian cancer, Prognostic biomarker, PI3K/AKT/mTOR signaling pathway original author(s) and the source, provide a link to the Creative Commons licence, and indicate if changes were made. The images or other third party material in this article are included in the article's Creative Commons licence, unless indicated otherwise in a credit line to the material. If material is not included in the article's Creative Commons licence and your intended use is not permitted by statutory regulation or exceeds the permitted use, you will need to obtain permission directly from the copyright holder. To view a copy of this licence, visit http://creativecommons.org/licenses/by/4.0/. The Creative Commons Public Domain Dedication waiver (http://creativeco mmons.org/publicdomain/zero/1.0/) applies to the data made available in this article, unless otherwise stated in a credit line to the data. 


\section{Introduction}

EOC is the most common histotype of OC [1-3], which is a highly aggressive and lethal cancer among gynecologic cancers. Statistical data indicated that almost $70 \%$ of $\mathrm{OC}$ cases remain undetected until the advanced stage [4]. Currently, the standard treatment for advanced OC is primary cytoreductive surgery followed by combination chemotherapy using platinum and taxane [4-6]. Tumor recurrence may ultimately occur in approximately $75 \%$ of patients with advanced OC, and in $20 \%$ of the cases, the tumors become resistant [7]. Early diagnosis and new treatment strategies for $\mathrm{OC}$ have been around for the last three decades. However, effective anticancer drugs for the treatment of $\mathrm{OC}$ are still lacking, and extensive research in this regard is warranted [2, 8-10]. Therefore, it is necessary to clarify the underlying biological mechanism of EOC so as to develop effective novel anticancer drugs for it. A previous study reported that the expression of TRiC mRNAs increased over four-fold after OC cells became resistant to cisplatin after being exposed to it in an in vitro study [11].

$\mathrm{TRiC}$ is an important eukaryotic chaperonin [12-14]. It has double rings stacked back-to-back, with an empty central cavity [15]; each ring contains eight different, yet paralogous subunits (TCP1, CCT2, CCT3, CCT4, CCT5, CCT6, CCT7, and CCT8) $[9,16]$. Each subunit has a molecular mass of approximately $60 \mathrm{kDa}$ [12] and can recognize proteins of different polarities and hydrophobic subunits [17]. A recent study suggested that high mRNA expression of TCP1 was significantly associated with poor overall survival (OS) in patients with breast cancer [18]. TCP1 was essential for survival in breast cancer, and it was regulated by oncogene activation driven by PI3K signaling [19].

However, the functional role of TCP1 in EOC is still unclear. Therefore, we investigated the protein expression of TCP1 in EOC tissues and analyzed its prognostic value for patients with EOC to demonstrate the role of TCP1 in the growth and survival of OC cells. Subsequently, we knocked down TCP1 using related shRNA and evaluated its roles in the proliferation, invasion, and migration of EOC cells. Finally, we explored the possible mechanism underlying the function of TCP1 in the development of OC cells.

\section{Material and methods}

\section{Tissue samples and patient data}

The ethics approval for present study was obtained from the Ethics Committee of the Fujian Medical University Union Hospital. We collected 109 formalin-fixed paraffin-embedded ovarian tissue, including 13 normal ovarian tissue chips, 26 ovarian cystadenoma chips, 8 border ovarian tumour chips, and 62 ovarian malignant tumour chips from patients treated initially at the Fujian Medical University Union Hospital between 2016 and 2019. Relevant clinical parameter data were collected from the hospital medical record system and the definite histological diagnosis and grading came from the pathological reports. The clinical-stage were determined based on the International Federation of Gynecology and Obstetrics, 2009 (FIGO, 2009).

\section{IHC and quantitative analysis}

Serial 3- $\mu \mathrm{m}$ sections from all samples were deparaffinized and rehydrated through xylenes and serial graded ethanol to water followed by antigen retrieval. These samples then were incubated overnight at $4{ }^{\circ} \mathrm{C}$ with TCP1 alpha primary antibody (Abcam Corporation; 1:200). The washed tissue samples were incubated with secondary antibody IgG (Merck Millipore; 1:300) for $30 \mathrm{~min}$ at room temperature (RT). Tissue slices were stained with 3,3'-diaminobenzidine and hematoxylin, and observed under an optical microscope. Finally, all images were analyzed integrated optical density (IOD) to calculate the average IOD /TCP1 positive staining area $\left(\mu \mathrm{m}^{2}\right)$ using Image-pro plus software.

\section{Survival analysis using KM plotter}

The correlation between TCP1mRNA (Affymetrix ID: 222010_at) expression and survial rate of OC was analyzed using the Kaplan Meier plotter (http://kmplot.com/ analysis). The cut-off date was set as overall survival (OS) and progression-free survival (PFS). The ruslt was presented with the hazard ratio (HR) and computed log rank $p$-value.

\section{Cell culture}

The human EOC cell line A2780 and normal ovarian cell IOSE-80 were purchased from the Bena Culture Collection (Kunshan, Jiangsu Province, China) and cultured in $5 \% \mathrm{CO}_{2}$ at $37{ }^{\circ} \mathrm{C}$ in dulbecco's modified eagle medium (DMEM; Gibco) added with $10 \%$ fetal bovine serum (FBS; Gibco). Another EOC cell SKOV3 was obtained from Guangzhou Cellcook Biotech Company and cultured in $5 \% \mathrm{CO}_{2}$ at $37{ }^{\circ} \mathrm{C}$ in McCoy's 5a supplemented with $10 \%$ FBS. Cell line authentication by short tandem repeat (STR) profiling.

\section{Western blot assay}

Total protein $(20 \mu \mathrm{g} / \mathrm{lane})$ was separated by polyacrylamide gel electrophoresis and then transferred to a PVDF membrane. Then, the membrane was blocked with 5\% non-fat dry milk solution and incubated with the various primary antibodies at $4{ }^{\circ} \mathrm{C}$ overnight. Next day, the washed membrane using tris buffered saline tween (TBST) was incubated with horse radish peroxidase 
(HRP) conjugated secondary antibodies at RT for $2 \mathrm{~h}$ followed by visualized using chemiluminescent HRP substrate (Merck Millipore) on a Western blot imaging system. The band intensity was detected using Image Lab software. The protein expression was normalized to glyceraldehydes 3-phosphate dehydrogenase (GAPDH) expression. The primary antibodies used were antiTCP1 alpha Rabbit Monoclonal (Abcam Corporation; 1:1,000), anti-mTOR Rabbit antibody (Abcam Corporation; 1:1,000), Akt antibody (CST Corporation, 1:1,000), phospho-Akt(Ser473) Rabbit mAb (CST Corporation, 1:1,000), and anti-GAPDH Mouse (TransGen Biotech, 1:2,000). Anti-mouse (Merck Millipore, 1:20,000) and anti-rabbit (Merck Millipore, 1:20,000) secondary antibodies were used.

\section{Construction of stable TCP1-knockdown cell line}

The pLKO.1 Puro vector was used to construct lentiviruses for TCP1 RNA interference (shTCP1) and negative control (shCtr) experiments. The sequences targeting TCP1 were designed based on the human TCP1 gene (Table 1) and synthesized according to the pLKO.1 Puro vector specification. To prepare lentiviral particles, $8 \mu \mathrm{g}$ of the shTCP1 vector (pLKO.1 Puro) and the packaging plasmids ( $5 \mu \mathrm{g}$ pMDL, $3 \mu \mathrm{g}$ pVSVG, and $2 \mu \mathrm{g}$ pREV) were cotransfected into $293 \mathrm{~T}$ cells. The TCP1-NC group was transfected with negative lentivirus. Lentivirus-containing medium was collected after $48 \mathrm{~h}$ of transfection and used to culture A2780 cells. After $48 \mathrm{~h}$ of transfection, the medium was replaced with complete medium. Then, puromycin with a final concentration of $2.0 \mu \mathrm{g} / \mathrm{mL}$ was added for stable cell line screening for $72 \mathrm{~h}$. Then, the survived cells were collected for TCP1 expression analysis. The stable cell lines were constructed in A2780/ TCP1- negative control group (NC) and A2780/TCP1knockdown group (KD), which were used for subsequent experimentation.

\section{MTT assay}

The proliferation of A2780/TCP1-NC and A2780/TCP1KD cells was detected by MTT assay. The cells were

Table 1 The TCP1 shRNA sequences

\begin{tabular}{ll}
\hline Name & Sequence $\left(\mathbf{5}^{\prime} \mathbf{- 3}^{\prime} \mathbf{)}\right.$ \\
\hline shTCP1 sense & CCGGGGTGTACAGGTGGT \\
& CATTATTCAAGAGATAAT \\
& GACCACCTGTACACCTTT \\
shTCP1 anti-sense & ATT \\
& ATTCAAAAAAGGTGTAC \\
& GATGGTCATTATCTCTT \\
& CACC \\
\hline
\end{tabular}

firstly inoculated to 96 -well plates (1,000 cells/well) and cultured in a humidified $5 \% \mathrm{CO}_{2}$ incubator at $37{ }^{\circ} \mathrm{C}$. Then, the plates were added with methyl thiazolyl tetrazolium (MTT, $0.5 \mathrm{mg} / \mathrm{mL}, 10 \mu \mathrm{L} /$ well) at $24,48,72$, and $96 \mathrm{~h}$. After $4 \mathrm{~h}$ of normal culture, the supernatant was removed and purple formazan crystals were dissolved using a $150 \mu \mathrm{L}$ dimethyl sulfoxide (DMSO) solution. The plate oscillated for $10 \mathrm{~min}$ at RT. The optical density at $490 \mathrm{~nm}$ (OD490) of each well was measured by microplate reader using wells without cells as blanks. The cell viability curve was drawn by the abscissa of the time point and the ordinate of OD value. Each experiment was performed in triplicate.

\section{Colony formation assay}

Infected cells were routinely harvested, resuspended, and then placed in 6-well plates (1000 cells/well) to analyze cell colony formation. After 10 days of incubation with each 3-day medium changes, the surviving cells were washed using cold phosphate buffered solution (PBS), fixed by $4 \%$ polyformaldehyde, and dyed with $1 \%$ crystal violet. The colonies with more than 50 cells were counted. We divided colony number by plated cell number to calculate the colony forming efficiency (CFE, \%). The experiments were repeated three times.

\section{Wound-healing assay}

Approximately $2 \times 10^{6}$ cells were seeded in 6-well plates. The cell monolayers were scratched using sterile $200-\mu \mathrm{l}$ pipette tips after reaching $80 \%$ confluence. Serum-free medium was added into the plates after washing the floating cells. Cells were cultured at $37{ }^{\circ} \mathrm{C}$ for $48 \mathrm{~h}$. The wound width was photographed and recorded every $24 \mathrm{~h}$. The results were observed using the Image J software. Wound closure was computed according to the ratio of districts uncovered by cells before and after wound scratching.

Table 2 The average optic density of TCP1 in ovary tissues in different histological subtype groups (IOD/area)

\begin{tabular}{lll}
\hline Group & $\mathbf{n}$ & IOD/area \\
\hline Normal & 13 & $0.003 \pm 0.004$ \\
Cystadenoma & 26 & $0.011 \pm 0.015$ \\
Borderline & 8 & $0.059 \pm 0.050^{\mathrm{a}, \mathrm{b}}$ \\
Carcinoma & 62 & $0.077 \pm 0.042^{\mathrm{c}, \mathrm{d}}$ \\
\hline
\end{tabular}

Data presented as mean $\pm S D$

a $P=0.001$ vs. normal

${ }^{\mathrm{b}} p=0.001$ vs. cystadenoma

c $P=0.000$ vs. normal

${ }^{\mathrm{d}} p=0.000$ vs. cystadenoma 


\section{Cell invasion and migration assay}

Transwell $(8-\mu \mathrm{m}$ pore size) chambers (Falcon) were coated with matrigel, placed in 24-well cell culture plates, and then air-dried in the incubator for $4 \mathrm{~h}$. The $50 \mu \mathrm{L}$ complete medium was added into each pore at $37^{\circ} \mathrm{C}$ for 30 min. A2780/TCP1-NC and A2780/TCP1-KD cells were cultured with 5\% FBS medium. Suspended cells $\left(15 \times 10^{4}\right.$ cells $\left./ 200 \mu \mathrm{L}\right)$ were added into the upper chamber and $600 \mu \mathrm{l} 15 \%$ FBS medium as a chemoattractant was put into the lower chamber. The invasive cells on the outside of the chamber were stained with $0.5 \%$ crystal violet after $48 \mathrm{~h}$ incubation. The cell slides were photographed under an inverted microscope in 5 randomlyselected fields at $\times 200$ magnification.
For migration assays, the Transwell chambers were not coated with matrigel and the follow-up procedure was consistent with the invasion assays. Each experiment was conducted three times.

\section{Statistical analysis}

All the data were represented as the mean \pm standard deviation (SD). Statistical analyses were carried out by the SPSS software (version 20.0; SPSS) and Graph Pad Software (Graph Pad Prism 8.0.1). The independent $t$-test was used to the comparison of two groups. The one-way analysis of variance (ANOVA) followed by post-hoc test was applied for comparing multiple groups. $P<0.05$ was considered as statistically significant.

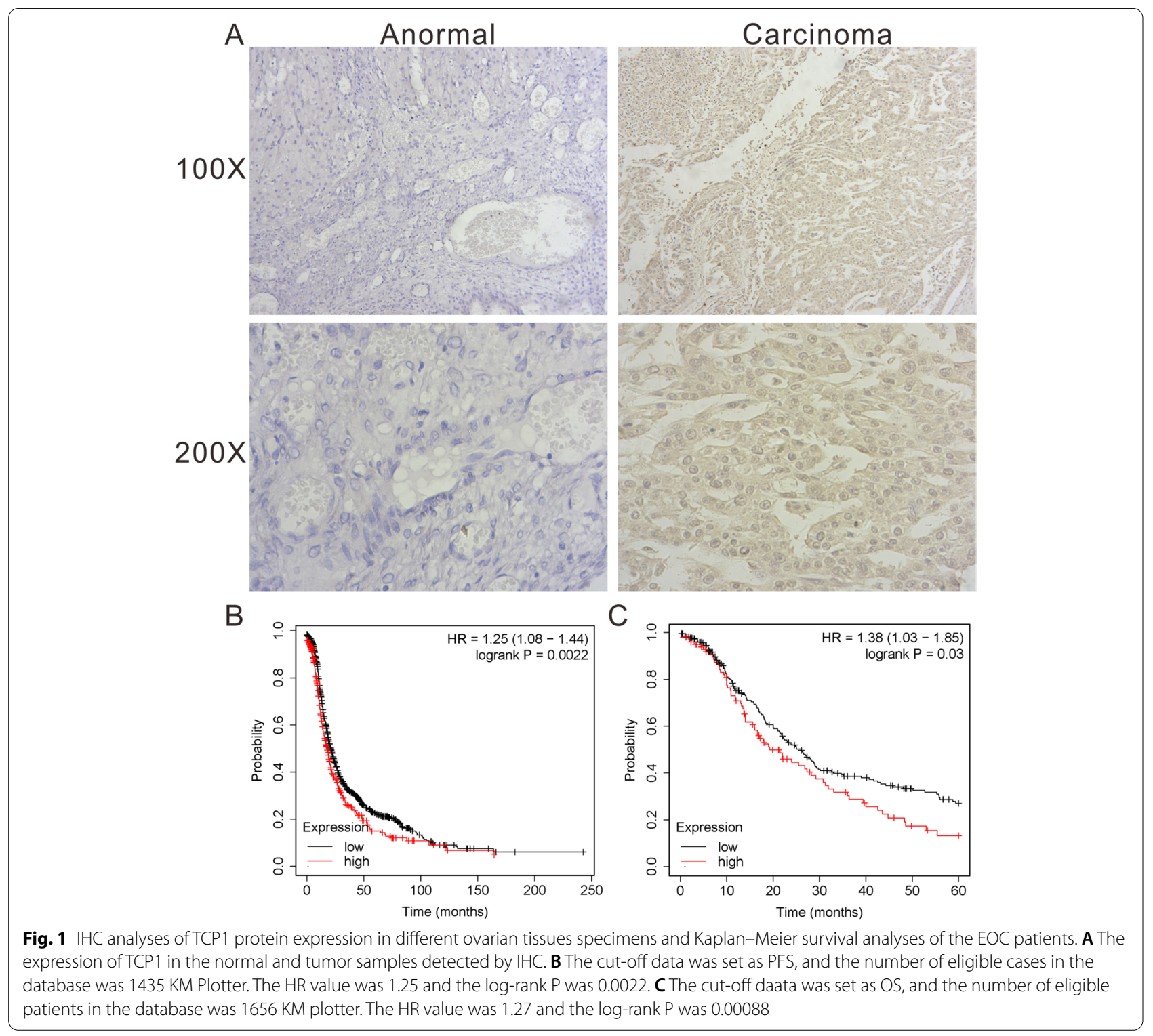




\section{Results}

TCP1 was abundantly expressed in EOC tissues and its expression was significantly associated with the grade of differentiation and FIGO stage

Compared with non-EOC tissues, the staining intensity of TCP1 in EOC tissues was significantly higher, as per immunohistochemistry (IHC) assay $(P<0.05)$ (Table 2$)$ (Fig. 1A). The relationships between the clinicopathologic variables of EOC and TCP1 expression are summarized in Table 3. ANOVA showed that the level of TCP1 expression correlated with the FIGO stage (the difference was statistically significant, $P=0.001$ ) and the grade of differentiation (the difference was statistically significant, $P=0.001$ ) but not with the tumor size, age, pathological type, lymph node metastasis, and volume of ascites. In summary, TCP1 upregulation may be associated with advanced stage of $\mathrm{OC}$.

Table 3 Relationship between TCP1 expression and clinicopathological features of EOC patients

\begin{tabular}{|c|c|c|c|}
\hline Characteristics & $\mathbf{N}$ & IOD/area & $P$ \\
\hline Age (years) & & & 0.271 \\
\hline$<60$ & 47 & $0.074 \pm 0.043$ & \\
\hline$\geq 60$ & 15 & $0.087 \pm 0.037$ & \\
\hline Tumour size & & & 0.72 \\
\hline$<5 \mathrm{~cm}$ & 14 & $0.074 \pm 0.037$ & \\
\hline$\geq 5 \mathrm{~cm}$ & 48 & $0.078 \pm 0.043$ & \\
\hline FIGO Stage (2009) & & & $0.001^{*}$ \\
\hline $1+\|$ & 30 & $0.060 \pm 0.033$ & \\
\hline$I I I+I V$ & 32 & $0.094 \pm 0.043$ & \\
\hline Histological subtype & & & 0.052 \\
\hline Serous & 38 & $0.086 \pm 0.044$ & \\
\hline Mucinous & 17 & $0.065 \pm 0.026$ & \\
\hline Clear cell & 4 & $0.014 \pm 0.007$ & \\
\hline Endometrioid & 3 & $0.091 \pm 0.069$ & \\
\hline Grade of differentiation $^{a}$ & & & $0.001^{*}$ \\
\hline Low & 27 & $0.050 \pm 0.023$ & \\
\hline High & 35 & $0.091 \pm 0.042$ & \\
\hline Lymph node metastasis $^{b}$ & & & 0.137 \\
\hline Positive & 9 & $0.100 \pm 0.048$ & \\
\hline Negative & 47 & $0.073 \pm 0.040$ & \\
\hline The volume of ascites & & & 0.27 \\
\hline Positive & 29 & $0.083 \pm 0.039$ & \\
\hline Negative & 33 & $0.072 \pm 0.044$ & \\
\hline
\end{tabular}

$N$ Number of patients

${ }^{*} P<0.05$

${ }^{\mathrm{a}}$ Low $=\mathrm{G} 1 ;$ High $=(\mathrm{G} 2+\mathrm{G} 3)$

${ }^{\mathrm{b}}$ Additional six cases did not undergo retroperitoneal lymphadenectomy
High expression of TCP1 mRNA led to a poor prognosis of patients with $\mathrm{OC}$

We evaluated the prognostic significance of TCP1 in patients with OC using the Kaplan-Meier plotter analysis tool. We observed that patients with $\mathrm{OC}$ who had a higher TCP1 expression had a shorter progression-free survival (PFS) $(\mathrm{HR}=1.25, P=0.0022, n=1453$, Fig. $1 \mathrm{~B})$. High TCP1 mRNA levels were also associated with poor OS $(\mathrm{HR}=1.27, P=0.00088, n=1656$, Fig. $1 C)$. The above results indicated that higher TCP1 mRNA levels predicted poor OS and PFS in patients with OC.

\section{Expression of TCP1 protein was upregulated in EOC cell line A2780}

TCP1 protein expression was evaluated by Western blotting in EOC cell lines A2780 and SKOV3. TCP1 was overexpressed in A2780 cells $(P<0.01)$ but not in SKOV3 cells, compared with normal cells IOSE-80 (Fig. 2A and B).

\section{TCP1 mRNA expression was inhibited in A2780 cells}

Based on the different levels of two EOC cells detected by Western blotting (Fig. 2A and B), A2780 cells with high levels of TCP1 expression were selected for transfection with TCP1 shRNA lentivirus, and the stable TCP1 knockdown cells were cultured to study the function of TCP1 and its mechanism of action in EOC cells. After infection, knockdown of TCP1 protein expression in A2780 cells was confirmed by Western blotting (Fig. 2C and D).

\section{TCP1 knockdown inhibited cell growth in vitro}

Cell proliferation assay using MTT and colony formation assays were performed to uncover the role of TCP1 in cancer cell growth. The cell viability of A2780/TCP1KD was clearly suppressed compared with that of A2780/ TCP1-NC (Fig. 3A); a similar finding was observed with regard to the colony-forming abilities $(P<0.01$, Fig. $3 \mathrm{~B}$ and $C$ ). The results of these assays demonstrated that TCP1 was essential for the growth of OC cells.

\section{TCP1 knockdown inhibited invasion and migration of A2780 cells}

Wound-healing and transwell assays were performed to evaluate the migration and invasion abilities of A2780 cells after TCP1 silencing. The wound-healing assay showed that stable TCP1 knockdown inhibited the migration rate of A2780 cells, compared with controls (Fig. 4A and D). The transwell migration (Fig. 4B and E) and invasion (Fig. 4C and F) assays showed similar results. Collectively, these results demonstrated that TCP1 promoted cell migration and invasion in EOC. 

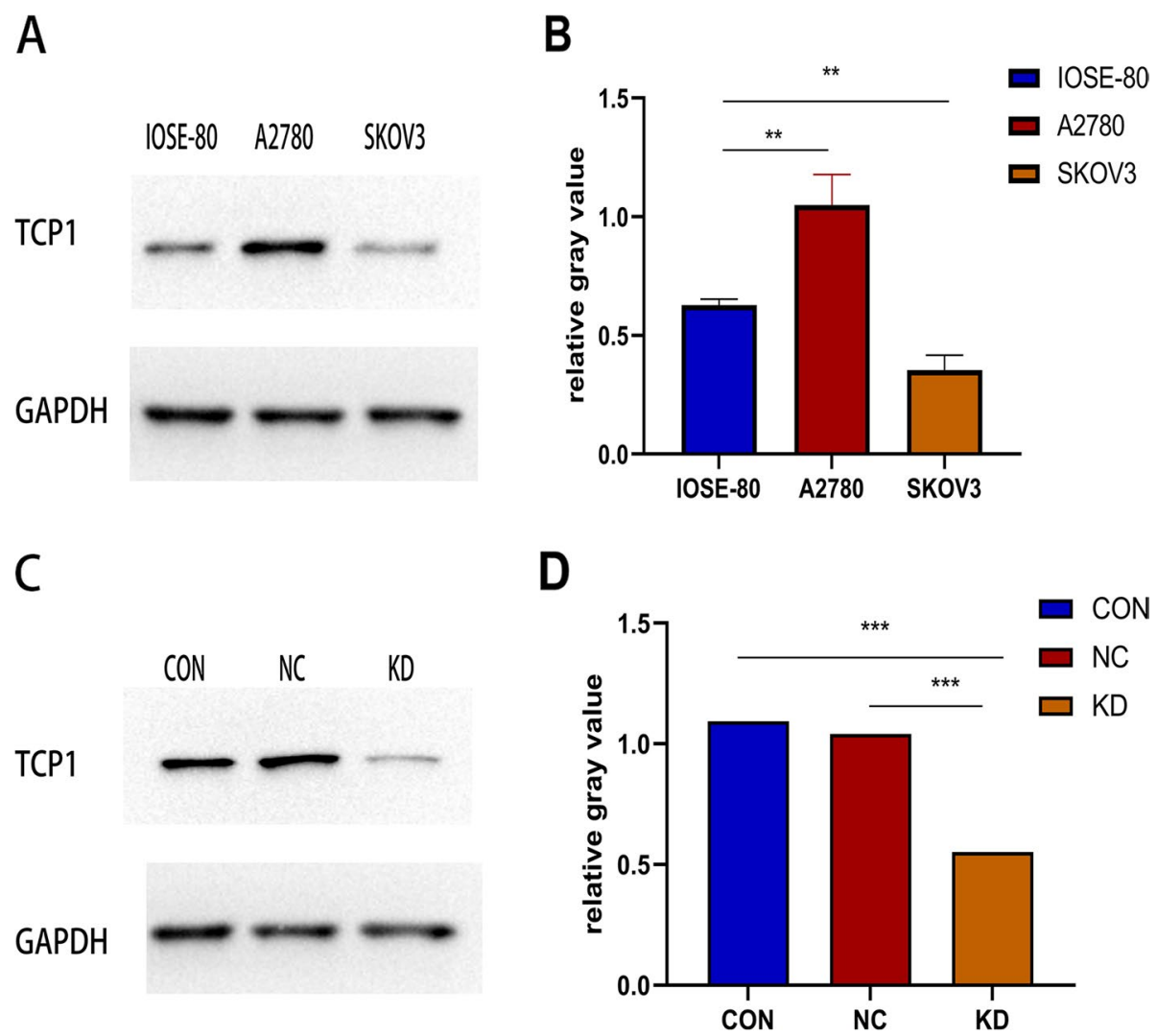

Fig. 2 The expression level of TCP1 protein in human EOC cell lines as evaluated by western blotting and the knockdown effect by shRNA against TCP1. A TCP1 protein was up-regulated in A2780 cells, but not in SKOV3 cells, compared with IOSE-80 cells. B Histogram plotted with three relative gray values from $\mathbf{A}$. Each cell line was conducted in triplicate. ${ }^{* *} P<0.01$ vs. IOSE-80. C The TCP1 expression levels of A2780/TCP1- KD cells that tested shRNA against TCP1 was markedly decreased, compared with A2780/TCP1-NC cells (NC: negative control) and A2780 cells control. (CON: controls). D Histogram plotted with three relative gray values from C. Each cell line was conducted in triplicate. ${ }^{* * *} P<0.001$ vs.A2780

TCP1 regulated $\mathrm{PI3K} / \mathrm{AKT} / \mathrm{mTOR}$ signaling through $\mathrm{p}-\mathrm{AKT}$ Protein was extracted from A2780/TCP1-NC and A2780/TCP1-KD cells. The results showed that phospho-AKT (p-AKT) and mTOR were decreased after TCP1 downregulation using Western blotting (Fig. 5A and B). GAPDH served as an internal control. Therefore, inhibition of TCP1 occurred via decrease of $\mathrm{p}-\mathrm{AKT}$ in the PI3K/AKT/mTOR pathway to inhibit the development of $\mathrm{OC}$, which was a central regulator of metabolism, survival, and proliferation in normal and cancer tissues.

\section{Discussion}

Through this study, we demonstrated that TCP1 protein, a member of $\mathrm{TRiC}$, is commonly altered in $\mathrm{OC}$, essential for the development of $\mathrm{OC}$ cells, and related to the prognosis of patients with OC. Our study findings indicate the roles of TCP1 in OC and suggest that TRiC could be a novel target for the treatment of OC. The survival data of over 1000 patients collected from the KM plotter demonstrate that TCP1 upregulation is related to the poor prognosis of patients with OC compared with patients with wild-type expression of TCP1. To further determine the roles of TCP1 in clinical studies, the formalin-fixed paraffin-embedded samples were stained for TCP1 via IHC and TCP1 expression was analyzed. Interestingly, TCP1 was overexpressed in EOC samples, especially in higher tumor grade and higher FIGO stage samples. The findings suggested that patients with upregulated TCP1 expression had more aggressive OC. Inhibitors targeting $\mathrm{TCP} 1$ or $\mathrm{TRiC}$ complex may be beneficial for the prognosis of patients with $\mathrm{OC}$ with higher TCP1 expression, if TCP1 decisively affects their phenotypes.

$\mathrm{TRiC}$, the most complex chaperonin, has eight distinct subunits encoded by different genes [12]. Originally, TRiC was identified and characterized by its essential role in folding cytoskeletal proteins such as tubulin and 


\section{A}

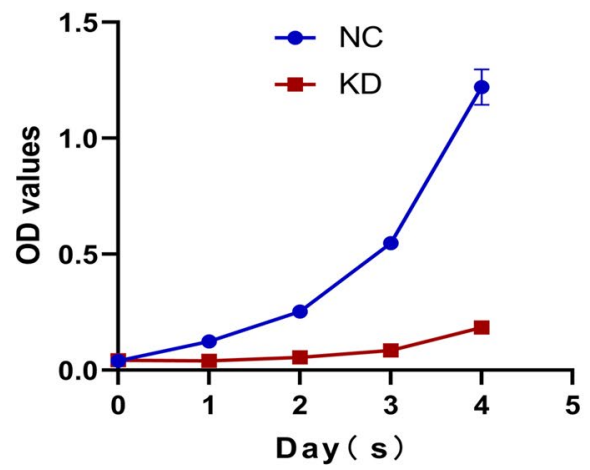

C

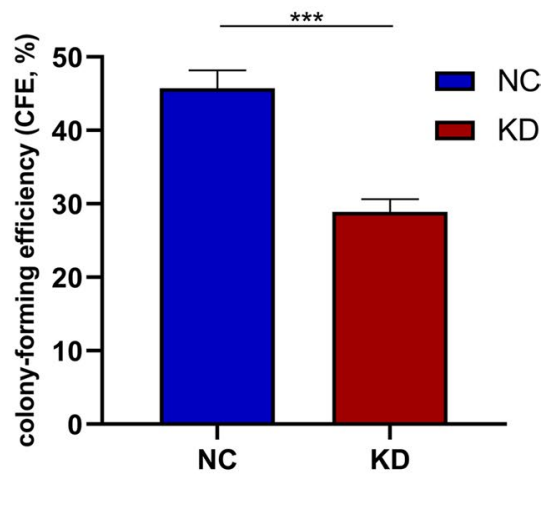

B
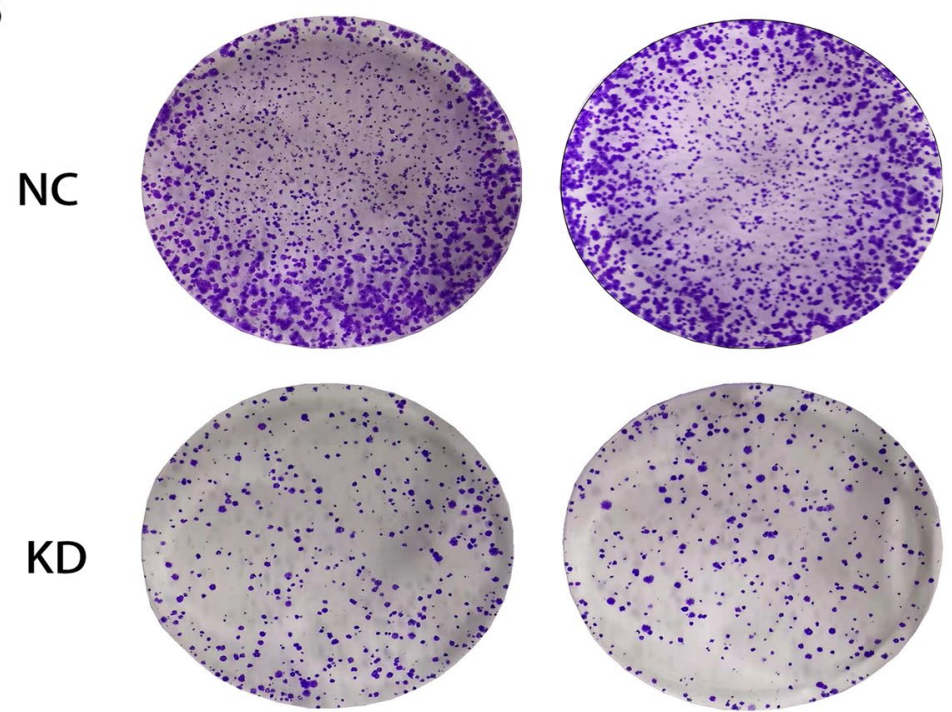

Fig. 3 Growth-inhibiting role of knockdown TCP1 in A2780 cell lines. A The MTT assay showed that with a dramatic decrease of TCP1 expression, the proliferation of A2780 cells was significantly inhibited as shown by a nearly flat growth curve. The difference arose from Day 1 and persisted until Day 4. B Colony-formation assays indicated decreased growth rates in TCP1-KD A2780 cell line. C The colony-formation abilities from (B). One independent experiment was carried out in triplicate. Values are shown as the mean \pm standard deviation (SD). Use independent Student's t-test to calculate $P$-values. ${ }^{* *} P<0.001$ vs. the NC

actin [14, 20, 21], cell cycle regulators Cdc20 [22], Cdh1 [22], p21ras oncoproteins [23], and the Von Hippel-Lindau tumor suppressor protein [3]. In addition, a previous study estimated that $5 \%$ of all cytoplasmic proteins in the eukaryotic cells are considered as components for the folding functions of TRiC [24]. Tubulins, one of the TRiC substrates, have been studied the most thoroughly and are the target of taxanes [25, 26], the common chemotherapy drugs for OC $[27,28]$. Tumor resistance to taxanes is a challenge in the treatment of OC. The facts that TRiC is essential for folding of tubulin and patients with OC with upregulated TCP1 expression have poor survival suggest that TCP1 may affect the sensitivity of patients to taxanes. Future studies are warranted to clarify the underlying targets of TRiC to enhance the sensitivity of OC cells to taxanes, thereby overcoming resistance to the drugs.

Currently, there are no available data about the functions of TRiC or TCP1 in OC cells. Hence, we aimed to study the functions of TCP1 in the growth and survival of OC cells. We observed that TCP1 is differentially expressed in the various OC cells. For instance, TCP1 was upregulated in the A2780 cell line, but not in the SKOV3 cell line, compared with IOSE- 80 cells, which is consistent with the findings of other studies [21]. This differential expression of TCP1 could be attributable to 

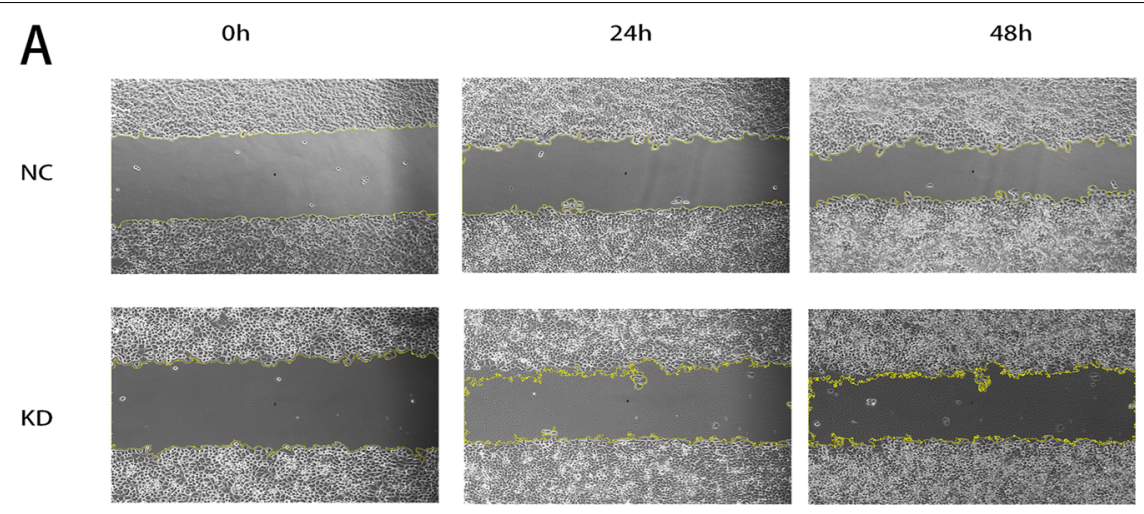

B

NC
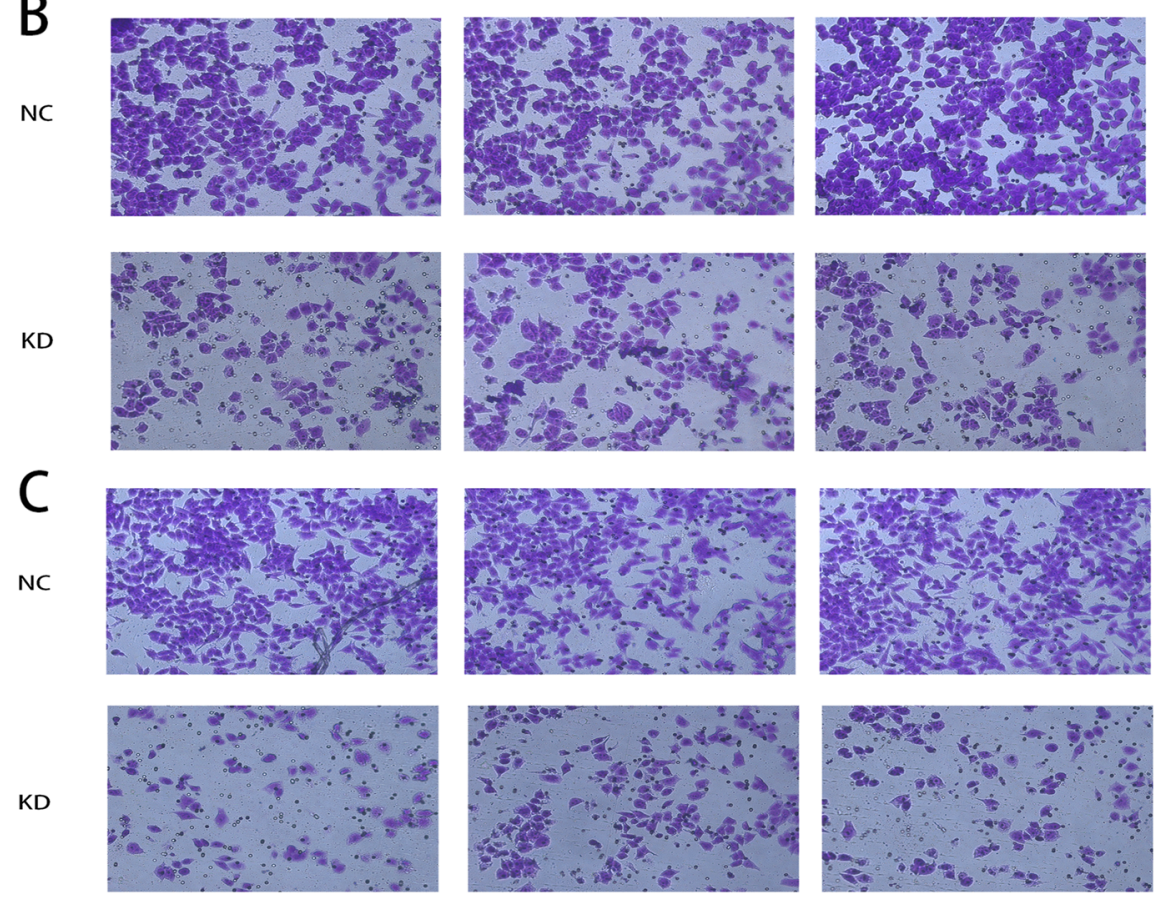

D

$E$
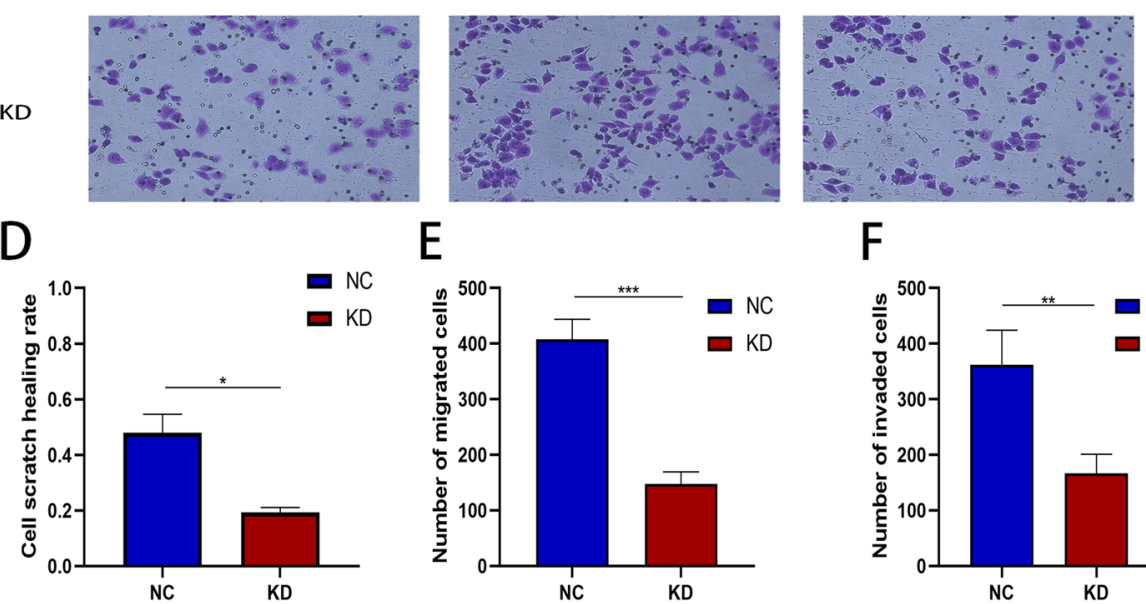

$\mathrm{F}$

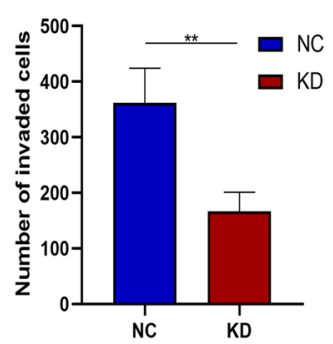

Fig. 4 Suppression of EOC cell migration and invasion ability by TCP1 silencing. A and D TCP1 knockdown in A2780 cell line inhibited cell migration, as revealed by a wound healing assay. $\mathbf{B}$ and $\mathbf{E}$ Transwell assays revealed that shRNA-TCP1 knockdown decreased the migration of A2780 cells. C and F TCP1 knockdown remarkably attenuated the invasion ability of A2780 cells. Data are presented as the mean \pm SD of three independent experiments. $P$-values were obtained with the independent Student's t-test. ${ }^{*} P<0.05$ vs. the NC; ${ }^{* *} P<0.01$ vs. the NC; ${ }^{* * *} P<0.001$ vs. the NC. Magnification: $200 \times$

the fact that EOC has several pathologically distinct subtypes, such as endometrioid, serous, clear cell, etc. [29]; although the two cell lines used in this study were derived from patients with adenocarcinoma-type OC, they may have come from tissues with different subtypes while preserving their individual phenotypes. For instance, 
A

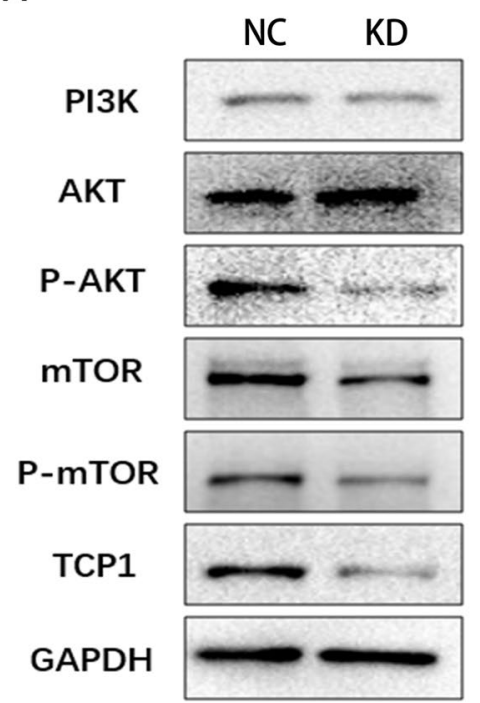

B

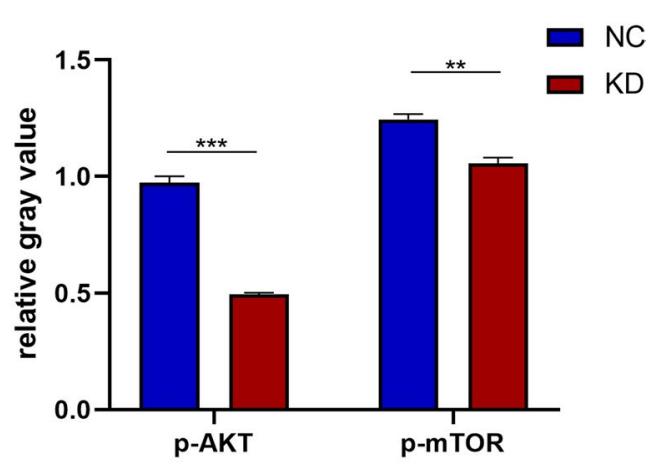

Fig. 5 Knockdown of TCP1 inhibited PI3K/AKT/mTOR pathway. A Phosphorylation levels of PI3K, AKT and mTOR by Western blot analysis. The GAPDH was used as an internal control. B Histogram plotted with three relative gray values from $(\mathbf{A})$. Data are presented as the mean \pm SD of three independent experiments. ${ }^{*} P<0.01$ vs. the NC; ${ }^{* *} P<0.001$ vs. the NC

compared with the OC cell line A2780, the cell line SKOV3 showed tenfold greater resistance to cisplatin and 5.8-fold greater resistance to carboplatin [30]. In addition, TCP1 or TRiC activity is not always correlated with its expression level [21]. Therefore, we selected the A2780 cell line and successfully constructed stable cell lines of the A2780/TCP1-NC group and A2780/TCP1-KD group by using specific lentiviral shRNA targeting TCP1, which were used for further analysis. The functional studies confirmed that the silencing of TCP1 inhibited the motility and aggression of $\mathrm{OC}$ cells. The results suggested that TCP1 can accelerate the malignancy of OC, which is consistent with the findings of other studies that involved other tumors.

A previous study confirmed that the effect of TCP1 is achieved via the PI3K/AKT pathway [19]. Based on the recent studies on cancer genomics, several genes in the major cell signaling pathways were dysregulated in OC $[8,9]$. Among these abnormal signaling pathways in $\mathrm{OC}$, the $\mathrm{PI} 3 \mathrm{~K} / \mathrm{AKT} / \mathrm{mTOR}$ pathway was altered frequently, providing a great chance for developing a therapeutic intervention for OC $[31,32]$. AKT, a known PI3-kinase target, is a serine-threonine kinase that regulates numerous downstream target genes [20,33], ultimately regulating metabolic processes and cellular survival [16]. To investigate the underlying molecular mechanisms by which TCP1 improves the proliferation, invasion, and migration of $\mathrm{OC}$ cells, some proteins involved in the $\mathrm{PI} 3 \mathrm{~K} / \mathrm{AKT} / \mathrm{mTOR}$ signaling pathway were tested in A2780 cells. As shown in Fig. 5, compared with total AKT content, p-AKT level at serine 473 (Ser473), one of the two phosphorylation sites on AKT for its activation, was lowered in A2780/ TCP1-KD cells [34]. Levels of p-AKT are typically determined to measure PI3K activity in cells. Altogether, the results showed that knockdown of TCP1 may inhibit the phosphorylation of AKT at Ser473 and its activation. In summary, TCP1 can regulate the proliferation, invasion, and migration of OC cells via the $\mathrm{PI} 3 \mathrm{~K} / \mathrm{AKT} / \mathrm{mTOR}$ pathway.

One possible limitation of this study is that the data were generated and analyzed from in vitro experiments. The specific mechanisms underlying the differential expression of TCP1 in the various OC cells and the possible regulation of $\mathrm{p}-\mathrm{AKT}$ expression in $\mathrm{OC}$ by TCP1 warrant further investigation.

\section{Conclusion}

In conclusion, TCP1 is overexpressed in OC and could be an important prognostic biomarker to predict the overall survival of patients with EOC. TCP1 may upregulate $\mathrm{p}-\mathrm{AKT}$, thereby promoting cell proliferation in $\mathrm{OC}$.

\footnotetext{
Abbreviations

TRiC: TCP1 ring complex; TCP1: T-complex protein 1; OC: Ovarian cancer; EOC: Epithelial ovarian cancer; PI3K: Phosphatidylinositol-3 kinase; P-AKT: PhosphoAKT; OS: Overall survival; PFS: Progression-free survival; shRNA: Short hairpin RNA; shTCP1: Lentiviruses for TCP1 RNA interference; shCtr: Lentiviruses for negative control.
} 


\section{Supplementary Information}

The online version contains supplementary material available at https://doi. org/10.1186/s13048-021-00832-x.

\section{Additional file 1.}

\section{Acknowledgements}

Not applicable.

\section{Authors' contributions}

HW designed the experiments and wrote the paper. ZZ, YL arranged the clinical data. HW, YL analyzed the data. HW, XF drafted the paper. ZZ, XF revised the final paper. The authors read and approved the final manuscript.

\section{Funding}

Fujian Provincial Department of Science and Technology (CN) (2100201).

\section{Availability of data and materials}

The datasets of the overall survival (OS), progression-free survival (PFS), risk ratio $(H R)$, and log-rank $P$ of TCP1 in OC patients analyzed during the current study are available in the Kaplan-Meier Plotter repository, [http://kmplot.com]. The datasets of clinical parameter data used and analyzed during the current study are available from the corresponding author on reasonable request.

\section{Declarations}

Ethics approval and consent to participate

This study was approved by the Ehics Committee of Fujian Medical University Union Hospital.

\section{Consent for publication}

Consent was obtained from all individual participants included in the study.

\section{Competing interests}

The authors declare that they have no competing interests.

Received: 25 September 2020 Accepted: 1 June 2021

Published online: 23 June 2021

\section{References}

1. Prat J. New insights into ovarian cancer pathology. Ann Oncol. 2012 https://doi.org/10.1093/annonc/mds300.

2. Jelovac D, Armstrong DK. Recent progress in the diagnosis and treatment of ovarian cancer. CA Cancer J Clin. 2011. https://doi.org/10. 3322/caac.20113

3. Hansen WJ, Ohh M, Moslehi J, Kondo K, Kaelin WG, Welch WJ. Diverse effects of mutations in exon II of the von Hippel-Lindau (VHL) tumor suppressor gene on the interaction of $\mathrm{pVHL}$ with the cytosolic chaperonin and pVHL-dependent ubiquitin ligase activity. Mol Cell Biol. 2002. https://doi.org/10.1128/mcb.22.6.1947-1960.2002.

4. Lan C, Li Y, Liu J. Intraperitoneal access via direct puncture is an alternative way to deliver intraperitoneal chemotherapy in ovarian, fallopian tube and primary peritoneal cancer. Gynecol Oncol. 2009. https://doi. org/10.1016/j.ygyno.2009.03.034

5. Katsumata N, Yasuda M, Takahashi F, et al. Dose-dense paclitaxel once a week in combination with carboplatin every 3 weeks for advanced ovarian cancer: a phase 3, open-label, randomised controlled trial. Lancet. 2009. https://doi.org/10.1016/s0140-6736(09)61157-0.

6. Gao Y, Li Y, Zhang C, et al. Evaluating the benefits of neoadjuvant chemotherapy for advanced epithelial ovarian cancer: a retrospective study. J Ovarian Res. 2019. https://doi.org/10.1186/s13048-019-0562-9.

7. Zheng L, Cui C, Shi O, et al. Incidence and mortality of ovarian cancer at the global, regional, and national levels, 1990-2017. Gynecol Oncol. 2020. https://doi.org/10.1016/j.ygyno.2020.07.008.
8. Gasparri ML, Bardhi E, Ruscito I, et al. PI3K/AKT/mTOR pathway in ovarian cancer treatment: are we on the right track? Geburtshilfe Frauenheilkd. 2017. https://doi.org/10.1055/s-0043-118907.

9. Dobbin ZC, Landen CN. The importance of the PI3K/AKT/MTOR pathway in the progression of ovarian cancer. Int J Mol Sci. 2013. https:// doi.org/10.3390/ijms14048213.

10. Keyvani V, Farshchian M, Esmaeili SA, et al. Ovarian cancer stem cells and targeted therapy. J Ovarian Res. 2019. https://doi.org/10.1186/ s13048-019-0588-z.

11. Vallin J, Grantham J. The role of the molecular chaperone CCT in protein folding and mediation of cytoskeleton-associated processes: implications for cancer cell biology. Cell Stress Chaperones. 2019. https://doi.org/10.1007/s12192-018-0949-3.

12. Lewis VA, Hynes GM, Zheng D, Saibil H, Willison K. T-complex polypeptide-1 is a subunit of a heteromeric particle in the eukaryotic cytosol. Nature. 1992. https://doi.org/10.1038/358249a0.

13. Gao Y, Thomas JO, Chow RL, Lee GH, Cowan NJ. A cytoplasmic chaperonin that catalyzes beta-actin folding. Cell. 1992. https://doi.org/10.1016/ 0092-8674(92)90622-j.

14. Frydman J, Nimmesgern E, Erdjument-Bromage $H$, Wall JS, Tempst $P$, Hartl FU. Function in protein folding of TRiC, a cytosolic ring complex containing TCP-1 and structurally related subunits. EMBO J. 1992;11(13):4767-78.

15. Colombo N, Sessa C, du Bois A, et al. ESMO-ESGO consensus conference recommendations on ovarian cancer: pathology and molecular biology, early and advanced stages, borderline tumours and recurrent diseaset. Ann Oncol. 2019. https://doi.org/10.1093/annonc/mdz062.

16. Ediriweera MK, Tennekoon KH, Samarakoon SR. Role of the PI3KJAKT/ mTOR signaling pathway in ovarian cancer: Biological and therapeutic significance. Semin Cancer Biol. 2019. https://doi.org/10.1016/j.semcancer. 2019.05.012.

17. Joachimiak LA, Walzthoeni T, Liu CW, Aebersold R, Frydman J. The structural basis of substrate recognition by the eukaryotic chaperonin TRiC/ CCT. Cell. 2014. https://doi.org/10.1016/j.cell.2014.10.042.

18. Xu WX, Song W, Jiang MP, Yang SJ, Zhang J, Wang DD, Tang JH. Systematic characterization of expression profiles and prognostic values of the eight subunits of the chaperonin TRiC in breast cancer. Front Genet. 2021 https://doi.org/10.3389/fgene.2021.637887.

19. Guest ST, Kratche ZR, Bollig-Fischer A, Haddad R, Ethier SP. Two members of the TRiC chaperonin complex, CCT2 and TCP1 are essential for survival of breast cancer cells and are linked to driving oncogenes. Exp Cell Res. 2015. https://doi.org/10.1016/j.yexcr.2015.02.005.

20. Altomare DA, Testa JR. Perturbations of the AKT signaling pathway in human cancer. Oncogene. 2005. https://doi.org/10.1038/sj.onc.1209085.

21. Alisi A, Boudiaf-Benmammar C, Cresteil T, Melki R. The cytosolic chaperonin CCT/TRiC and cancer cell proliferation. PLoS One. 2013. https://doi. org/10.1371/journal.pone.0060895.

22. Camasses A, Bogdanova A, Shevchenko A, Zachariae W. The CCT chaperonin promotes activation of the anaphase-promoting complex through the generation of functional Cdc20. Mol Cell. 2003. https://doi.org/10. 1016/s1097-2765(03)00244-2.

23. Seiden-Long IM, Brown KR, Shih W, et al. Transcriptional targets of hepatocyte growth factor signaling and Ki-ras oncogene activation in colorectal cancer. Oncogene. 2006. https://doi.org/10.1038/sj.onc.1209005.

24. Clarke AR. Cytosolic chaperonins: a question of promiscuity. Mol Cell. 2006. https://doi.org/10.1016/j.molcel.2006.10.002.

25. Lowe J, Li H, Downing KH, Nogales E. Refined structure of alpha betatubulin at 3.5 A resolution. J Mol Biol. 2001. https://doi.org/10.1006/jmbi. 2001.5077.

26. Nogales E, Wolf SG, Downing KH. Structure of the alpha beta tubulin dimer by electron crystallography. Nature. 1998. https://doi.org/10.1038/ 34465.

27. Seetalarom K, Kudelka AP, Verschraegen CF, Kavanagh JJ. Taxanes in ovarian cancer treatment. Curr Opin Obstet Gynecol. 1997:9(1):14-20.

28. Trimble EL, Arbuck SG, McGuire WP. Options for primary chemotherapy of epithelial ovarian cancer: taxanes. Gynecol Oncol. 1994. https://doi.org/ 10.1006/gyno.1994.1349.

29. Lino-Silva LS. Ovarian carcinoma: pathology review with an emphasis in their molecular characteristics. Chin Clin Oncol. 2020. https://doi.org/10. 21037/cco-20-31. 
30. Mon MT, Yodkeeree S, Punfa W, et al. Relationships of ex-vivo drug resistance assay and cytokine production with clinicopathological features in the primary cell culture of Thai ovarian and fallopian tube cancer patients. Asian Pac J Cancer Prev. 2017. https://doi.org/10.22034/APJCP. 2017.18.11.3063.

31. Mabuchi S, Kuroda H, Takahashi R, Sasano T. The PI3K/AKT/mTOR pathway as a therapeutic target in ovarian cancer. Gynecol Oncol. 2015. https:// doi.org/10.1016/j.ygyno.2015.02.003.

32. Li H, Zeng J, Shen K. PI3K/AKT/mTOR signaling pathway as a therapeutic target for ovarian cancer. Arch Gynecol Obstet. 2014. https://doi.org/10. 1007/s00404-014-3377-3.
33. Engelman JA. Targeting PI3K signalling in cancer: opportunities, challenges and limitations. Nat Rev Cancer. 2009. https://doi.org/10.1038/ nrc2664.

34. Vasudevan KM, Garraway LA. AKT signaling in physiology and disease. Curr Top Microbiol Immunol. 2010. https://doi.org/10.1007/82_2010_66.

\section{Publisher's Note}

Springer Nature remains neutral with regard to jurisdictional claims in published maps and institutional affiliations.
Ready to submit your research? Choose BMC and benefit from:

- fast, convenient online submission

- thorough peer review by experienced researchers in your field

- rapid publication on acceptance

- support for research data, including large and complex data types

- gold Open Access which fosters wider collaboration and increased citations

- maximum visibility for your research: over $100 \mathrm{M}$ website views per year

At BMC, research is always in progress.

Learn more biomedcentral.com/submissions 